\title{
CORRELATION ANALYSIS OF EAST ASIAN SUMMER MONSOON AND SUBSURFACE OCEAN TEMPERATURE FROM THE PACIFIC OCEAN TO THE INDIAN OCEAN IN THE TROPICS
}

\author{
LI, X. ${ }^{1}-$ TU, S. ${ }^{2, *}-$ TANG, Y. ${ }^{3}-$ LIU, L. ${ }^{4}$ \\ ${ }^{I}$ Civil Aviation Flight University of China \\ 618307 Guanghan, China \\ phone: +86 15881471506; fax: +8608385190242 \\ ${ }^{2}$ Faculty of Information Technology, Beijing University of Technology \\ 100124 Beijing, China \\ ${ }^{3}$ Deyang Meteorological Bureau \\ 618000 Deyang, China \\ phone: +86 18016136136; fax: +8608382403100 \\ ${ }^{4}$ Beijing Electro-Mechanical Engineering Institute \\ 100074 Beijing, China \\ phone: +86 13810171658; fax: +8601068742857 \\ *Corresponding author \\ e-mail: sstu@bjut.edu.cn; phone: +86 18618455499 \\ (Received $30^{\text {th }}$ Jun 2017; accepted $27^{\text {th }}$ Oct 2017)
}

\begin{abstract}
In order to offer some meaningful information on prediction of East Asian summer monsoon and ENSO, this paper mainly calculates the relativity between the East Asian summer monsoon and tropical upper sea temperature and makes a composite analysis to discuss the interactions of them. It turns out that: The best correlation between the Tropical Central Indian Ocean, the West Pacific Ocean to the East Indian Ocean and EASM index is at $120 \mathrm{~m}$. The positive and negative correlation zones move from west to east over time from the Pacific Ocean to the Indian Ocean in the tropics. If the sea temperature field in autumn and winter in the previous year shows the phenomenon of La Nina-like, the west wind from the East Indian Ocean to the West Pacific Ocean will strengthen from December to April. From March to April, there would be easterly wind anomaly air current on the East Pacific Ocean, and if Walker Circulation strengthens, it may occur strong monsoon in summer, and is easy to turn into the phenomenon of El Nino-like in autumn and winter. About their interactional physical process, should further strengthen the mechanism and model study in the future.
\end{abstract}

Keywords: El Nino, Walker circulation, composite analysis, upper sea temperature, correlation zone

\section{Introduction}

The land-sea thermal difference changes along with the change of season caused by the different distribution of sea and land on the surface of the earth is the main cause of monsoon. The variations of monsoon play an important role in seasonal and inter-annual variations of the world's tropical atmospheric circulation (Qian, 2000; Wang, 2010). The large amounts of water vapor in monsoon region from tropical oceans that brought by East Asian summer monsoon (EASM) has vital influence on the 
distribution of rainfall, the move of the zone of precipitation, drought and flood in most part of China. Therefore, the research on the relationship between the thermal condition of tropical oceans and EASM is of great significance. In the tropical oceans, ENSO is a strong signal of air-sea interaction (Wang et al., 2000; Xie et al., 2010; Li et al., 2013), which will cause serious climate anomaly in many areas around the world.

Many studies (Zhang et al., 1999; Li and Shou, 2000; Zong et al., 2010; Chen et al., 2013; Xu et al., 2016) have shown that ENSO has important influence on the East Asian summer monsoon and our climate. It is pointed out that the anomaly of sea surface temperature (SST) is the strongest and most important factor for the East Asian summer monsoon forecast, and the difference of the El Nino warming period affects the strength and outbreak time of EASM, thus affecting the amount of summer precipitation in East Asia. As the interaction of the Western Pacific Warm Pool (WPWP) in tropics was dramatic, studies (Huang and Sun, 1994a; Jin and Chen, 2002; Chen and Huang, 2008; Huang et al., 2016) proposed that the WPWP played a key role not only in the tropical Pacific ENSO cycle, but also in the intraseasonal and interannual variation of EASM. Meanwhile, the tropical Pacific ENSO cycle also affected large-scale circulation and convection activities over WPWP and EASM circulation.

The above researches are based on SST in tropics. However, because of the fact that the distribution of SST depended on the complex process of three-dimensional ocean circulation, the research on subsurface is equally important. As subsurface ocean temperature (SOT) has been less affected by external factors, in other words, it has high stability, which gradually aroused attentions of meteorologists in recent years. According to the research of $\mathrm{Li}$ and $\mathrm{Mu}$ (1999) and Mu and Li (2000), SOT in WPWP continued to rise before the onset of El Nino event. The positive anomaly of SOT in the warm pool region, especially the spread of it to the equatorial central and eastern pacific directly caused the onset of El Nino event. It was an important reason for El Nino event. The research on SOT in recent years further pointed out that the anomaly of SOT in WPWP and ENSO cycle were interacted with each other (Chen et al., 2010; Li and Li, 2014; Shan et al., 2016).

Thus can be seen that the influence that SST in the tropical ocean on EASM and the relationship between SOT in WPWP on the equator and ENSO have been taken seriously, But the relationship between subsurface temperature change and EASM is seldom considered. Zhang et al. (2001a; 2001b; 2002) found that the temperature anomaly distribution of SOT from the tropical Pacific Ocean to the Indian Ocean played an important part in onset's strength and time of South China Sea summer monsoon, and revealed the correlation of them. Nevertheless, the relationship between EASM and SOT from the Pacific Ocean to the Indian Ocean in the tropics remains unknown. Therefore, this paper strives to seek the distribution modes of sea temperature between strong and weak monsoon and reveals the interaction of them according to the analysis of EASM intensity index and SOT from the Pacific Ocean to the Indian Ocean in the tropics. 


\section{Materials and Methods}

A set of data about the monthly anomaly of the sea temperature in the world's upper ocean sorted out by Scripps Joint Environmental Data Analysis Center (JEDAC) in the United States was obtained from Nanjing Atmospheric Data Service Center. The horizontal resolution of which was $5^{\circ} \times 2^{\circ}$ with a coverage of $30^{\circ} \mathrm{E} \sim 180^{\circ} \sim 0^{\circ} \sim 30^{\circ}$ $\mathrm{E}, 60^{\circ} \mathrm{S} \sim 60^{\circ} \mathrm{N}$ and the locations of the monthly anomaly in vertical were $0,20,40,60,80,120,160,200,240,300,400 \mathrm{~m}$ from January 1955 to December 1998. This paper focused on the date of $30^{\circ} \mathrm{S} \sim 40^{\circ} \mathrm{N}$ in the Pacific-Indian Ocean with a total of 528 time levels.

NCEP/NCAR reanalysis data of monthly average wind field at $850 \mathrm{hPa}$ from January 1955 to December 1998 with a horizontal resolution of $2.5^{\circ} \times 2.5^{\circ}$.

The computing method of East Asia Summer Monsoon Index (EASMI) defined by Zhang et al. (2003) was to calculate the average anomaly annual temperature of zonal wind in the monsoon trough of East Asia tropical monsoon $\left(10 \sim 20^{\circ} \mathrm{N}, 100 \sim 150^{\circ} \mathrm{E}\right)$ and East Asia subtropical region $\left(25 \sim 35^{\circ} \mathrm{N}, 100 \sim 150^{\circ} \mathrm{E}\right)$ at $850 \mathrm{hPa}$ from June to August. That was $\mathrm{I}_{\mathrm{EASM}}=\mathrm{U}_{850 \mathrm{hPa}}\left(10 \sim 20^{\circ} \mathrm{N}, 100 \sim 150^{\circ} \mathrm{E}\right)-\mathrm{U}_{850 \mathrm{hPa}}\left(25 \sim 35^{\circ} \mathrm{N}, 100 \sim 150^{\circ} \mathrm{E}\right)$. The higher the value, the stronger the summer monsoon and vice versa. This paper selected the data from 1955 to 1998. After standardizing, the paper reckoned that if the intensity index of EASM is greater than 1.0, it is a strong summer monsoon year, while the intensity index of EASM is less than -1.0, it is a weak summer monsoon year. The interannual variability was shown in Figure 1. The main methods used were synthetic analysis method and correlation coefficient method.

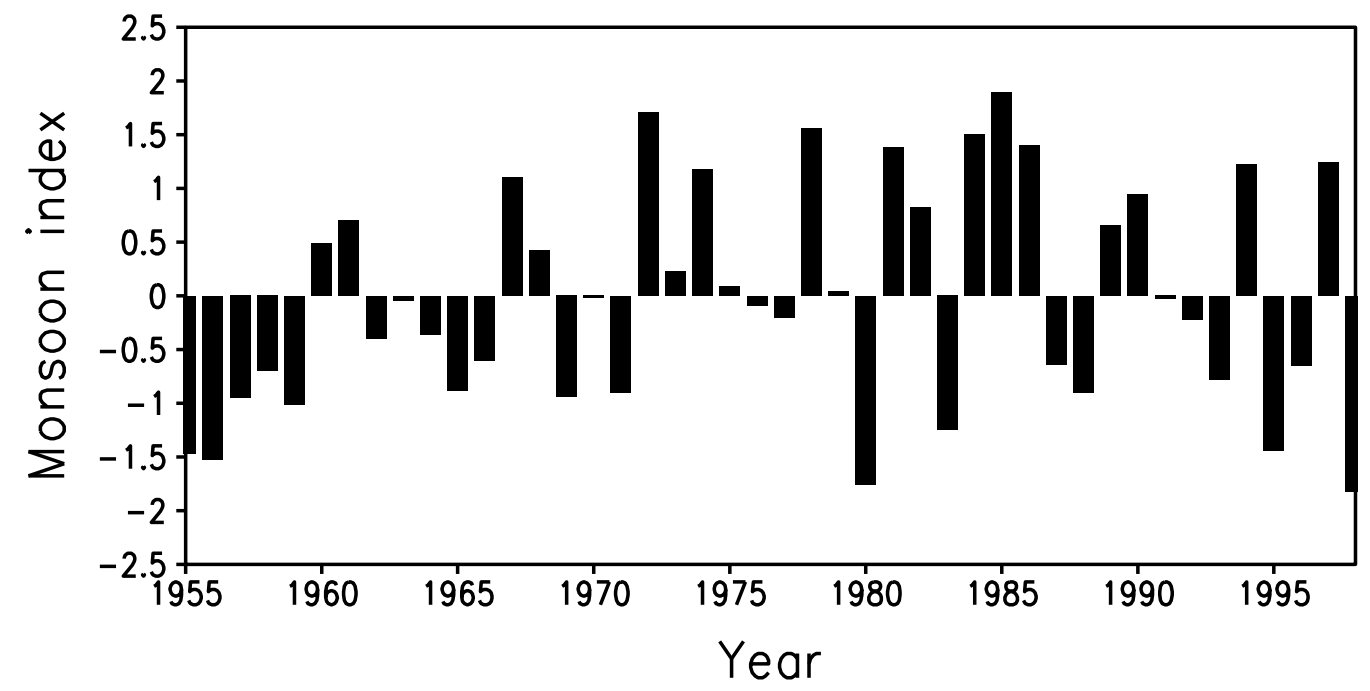

Figure 1. Interannual variability of the East Asia summer monsoon index from 1955 to 1998

\section{Correlation Analysis of the EASMI and Sea Temperature}

The formation of winter and summer monsoon circulations is related to the sea and land thermal regime in winter and summer. In summer, the land is a heat source that 
controlled by heat low and the sea is a cold source that controlled by cold high. According to the principle of gradient wind, the wind blows off anticyclone towards depression and thus formed the summer monsoon that blows off the sea towards the land. It can be seen that the sea thermal regime has significance influence on the variation of EASM circulation. Therefore, the paper firstly analyzed the relationship between EASM index and sea temperature.

After calculating EASM intensify index anomaly and sea temperature anomaly from the Pacific Ocean to the Indian Ocean in the tropics from $0 \mathrm{~m}$ to $400 \mathrm{~m}$ in monthly and analyzing the correlation filed in each level, this paper found out that the correlation distribution of the Indian Ocean, the West Pacific to the East Indian Ocean and the East Pacific region on the equator and the monsoon index changes over time.

\section{Results}

The average regional correlation field (Fig. 2) is given below, which shows the sea temperature that ahead of monsoon for 7 months and lagged behind monsoon for 4 months. The $\mathrm{a} \sim \mathrm{c}$ are the correlation distribution of sea temperature and monsoon index in the Indian Ocean $\left(15^{\circ} \mathrm{S} \sim 15^{\circ} \mathrm{N}, 60 \sim 80^{\circ} \mathrm{E}\right)$, the West Pacific to the East Indian Ocean $\left(15^{\circ} \mathrm{S} \sim 15^{\circ} \mathrm{N}, 100 \sim 170^{\circ} \mathrm{E}\right)$ and the East Pacific $\left(10^{\circ} \mathrm{S} \sim 10^{\circ} \mathrm{N}, 170 \sim 80^{\circ} \mathrm{W}\right)$ region on the equator in December in the previous year; $d \sim f$ is in November in the same year.

It could be seen that the value of the Indian Ocean Region (Fig. 2a) in December in the previous year demonstrated a negative correlation and the absolute value of the correlation distribution gradually decreased from $0 \mathrm{~m}$ to $60 \mathrm{~m}$, while from $60 \mathrm{~m}$ to $120 \mathrm{~m}$, this value gradually increased and the whole level showed a trend of shock weakening. The West Pacific to the East Indian Ocean Region (Fig. 2b) demonstrated a positive correlation and the correlation distribution gradually increased from $0 \mathrm{~m}$ to $120 \mathrm{~m}$, while from $120 \mathrm{~m}$ to $400 \mathrm{~m}$, this value gradually decreased and the whole level looked like a line "V", it reached the crest value at 120m. The East Pacific region (Fig. 2c) demonstrated a negative correlation and the absolute value of the correlation distribution in this whole level showed a trend of weakening, it reached the crest value at $40 \mathrm{~m}$. This paper found that the sea temperature that ahead of monsoon for 7 months in tropics was a mode of "- + -" from West to East and at 120m, the Central Indian Ocean, the West Pacific to the East Indian Ocean Region on the equator and monsoon index showed a good relativity. In November, the Central Indian Ocean Region (Fig. 2d) demonstrated a positive correlation and reached the crest value at $120 \mathrm{~m}$. The West Pacific to the East Indian Ocean Region (Fig. 2e) demonstrated a negative correlation, and the absolute value of the correlation distribution in the whole level was the same as the period that the sea temperature ahead of monsoon for 7 months. That was the correlation distribution gradually increased from $0 \mathrm{~m}$ to $120 \mathrm{~m}$, while from $120 \mathrm{~m}$ to $400 \mathrm{~m}$, this value gradually decreased and the whole level looked like a line " $\mathrm{V}$ " and reached the crest value at $120 \mathrm{~m}$. The East Pacific region (Fig. 2f) demonstrated a positive correlation and the absolute value of the correlation distribution in the whole level was the same as the period that the sea temperature ahead of monsoon for 7 months, too. It showed a trend of 


$$
-85 \text { - }
$$

weakening and reached the crest value at $40 \mathrm{~m}$. In summary, the sea temperature that lagged behind monsoon for 4 months in tropics was a mode of “+ - +"from West to East and the Central Indian Ocean, the West Pacific to the East Indian Ocean on the equator at $120 \mathrm{~m}$ and monsoon index showed a best relativity (Zhang et al., 2001b, 2002).
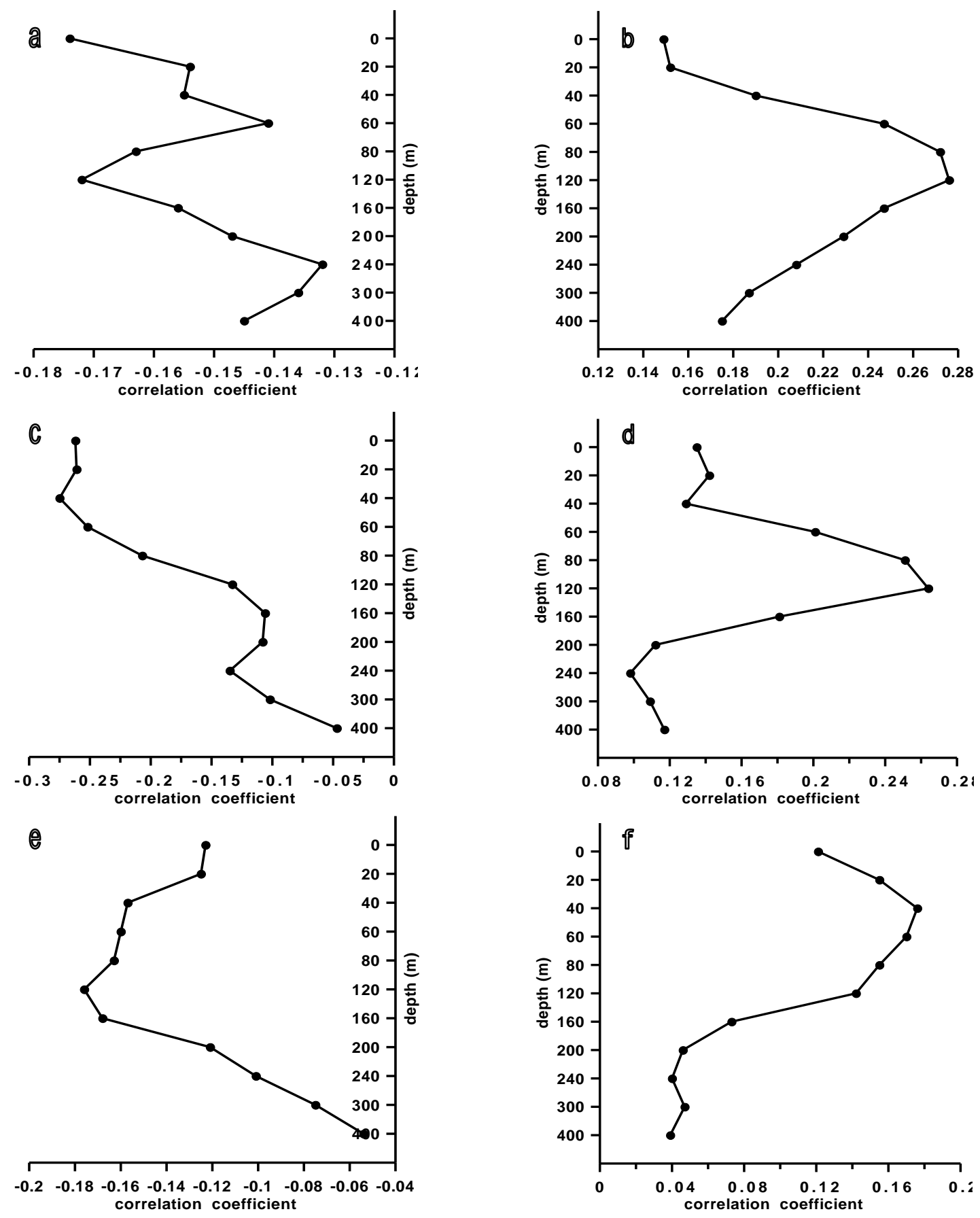

Figure 2. Correlation coefficient of area average between East Asia summer monsoon index and sea temperature in $0 \sim 400$ m layer 
Above all, the mode of the Central Indian Ocean, the West Pacific to the East Indian Ocean and the East Pacific Ocean region on the equator and monsoon index associated with the transition of " -+- " to "+ -+ " over time. The best relativity of the Central Indian Ocean, the West Pacific to the East Indian Ocean on the equator and EASM index occurred at $120 \mathrm{~m}$, while that of the East Pacific region on the equator and EASM index occurred at $40 \mathrm{~m}$. Which showed that the signal strength of EASM is the strongest in tropical sea subsurface. This result was consistent with Reference (Huang and Sun, 1994b). The reason for this phenomemon was that the depth of thermocline of the Indian Ocean in tropics is about $70 \mathrm{~m}$ to $100 \mathrm{~m}$, and the thermocline of the Pacific Ocean in tropics was gradually uplifting from West to East. The depth of which was $140 \mathrm{~m}$ in the West Pacific in tropics, while in the East Pacific on the equator, it was less than 50m (Mcphaden, 1999; Cai et al., 2005; Li et al., 2008). That was to say, the variation of anomaly at $120 \mathrm{~m}$ reflected the changes of the sea temperature in thermocline in most regions. After analyzing the correlation filed in each level, this paper found that the distribution pattern of the correlation filed from $0 \mathrm{~m}$ to $40 \mathrm{~m}$ is close to each other, and that of the correlation filed in each level from $60 \mathrm{~m}$ to $400 \mathrm{~m}$ is alike. This paper selected $40 \mathrm{~m}$ and $120 \mathrm{~m}$ which has the best relativity among those levels to do our research. Figure 3 was the distribution pattern of correlation field of these two kinds of sea temperature and EASM index. a $\sim d$ were the distribution pattern of correlation field that the sea temperature ahead of monsoon for 7 months, 3 months, the corresponding period and lagged behind monsoon for 4 months at 40m; e $\sim \mathrm{h}$ were the distribution pattern of correlation field that the sea temperature ahead of monsoon for 7 months, 3 months, the corresponding period and lagged behind monsoon for 4 months at $120 \mathrm{~m}$. After testing by 0.10 confidential level, this paper found that the correlation field of the shadow region that up to 0.40 is exceed the significance level of the shadow region that up to 0.01 .
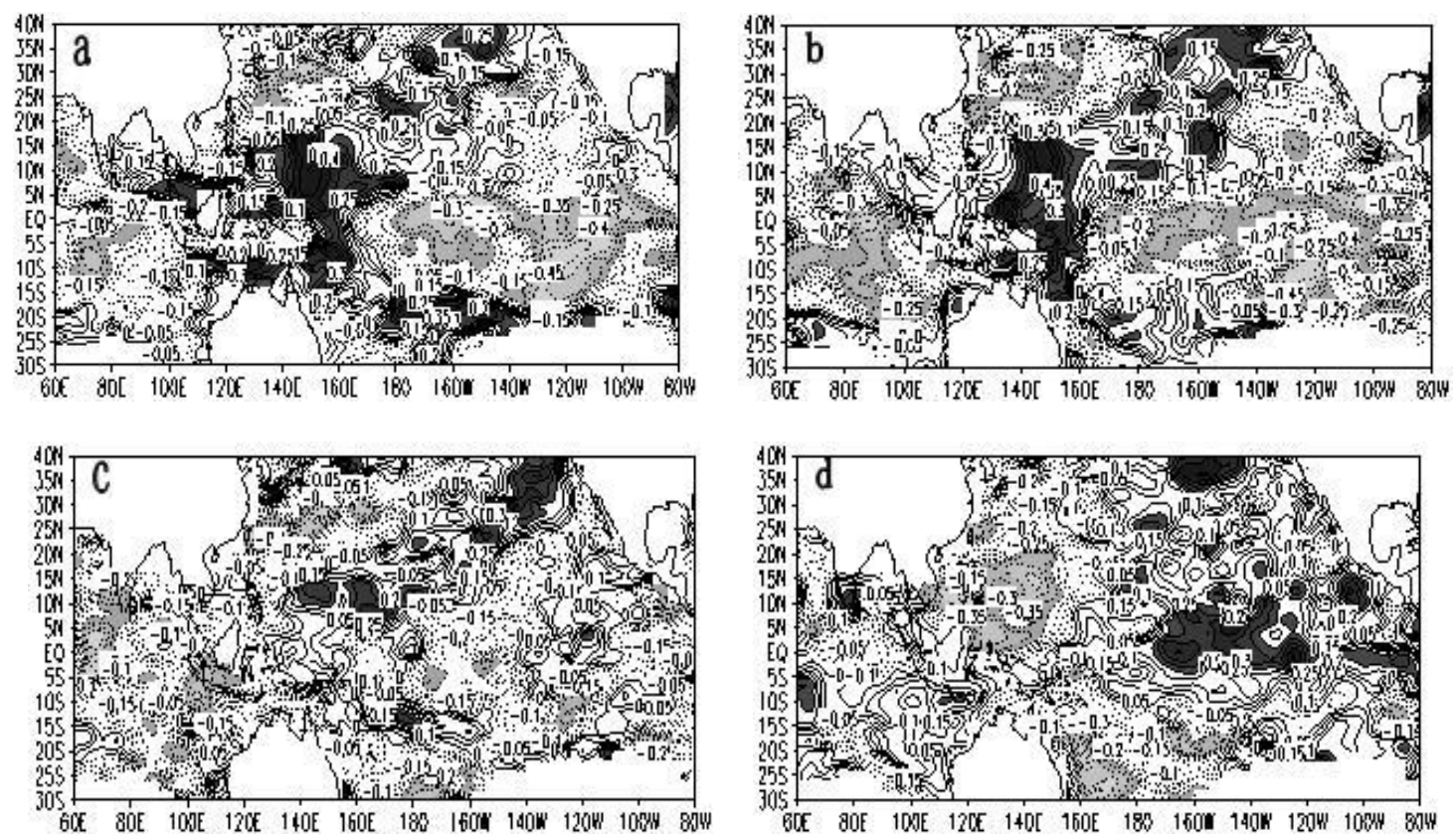

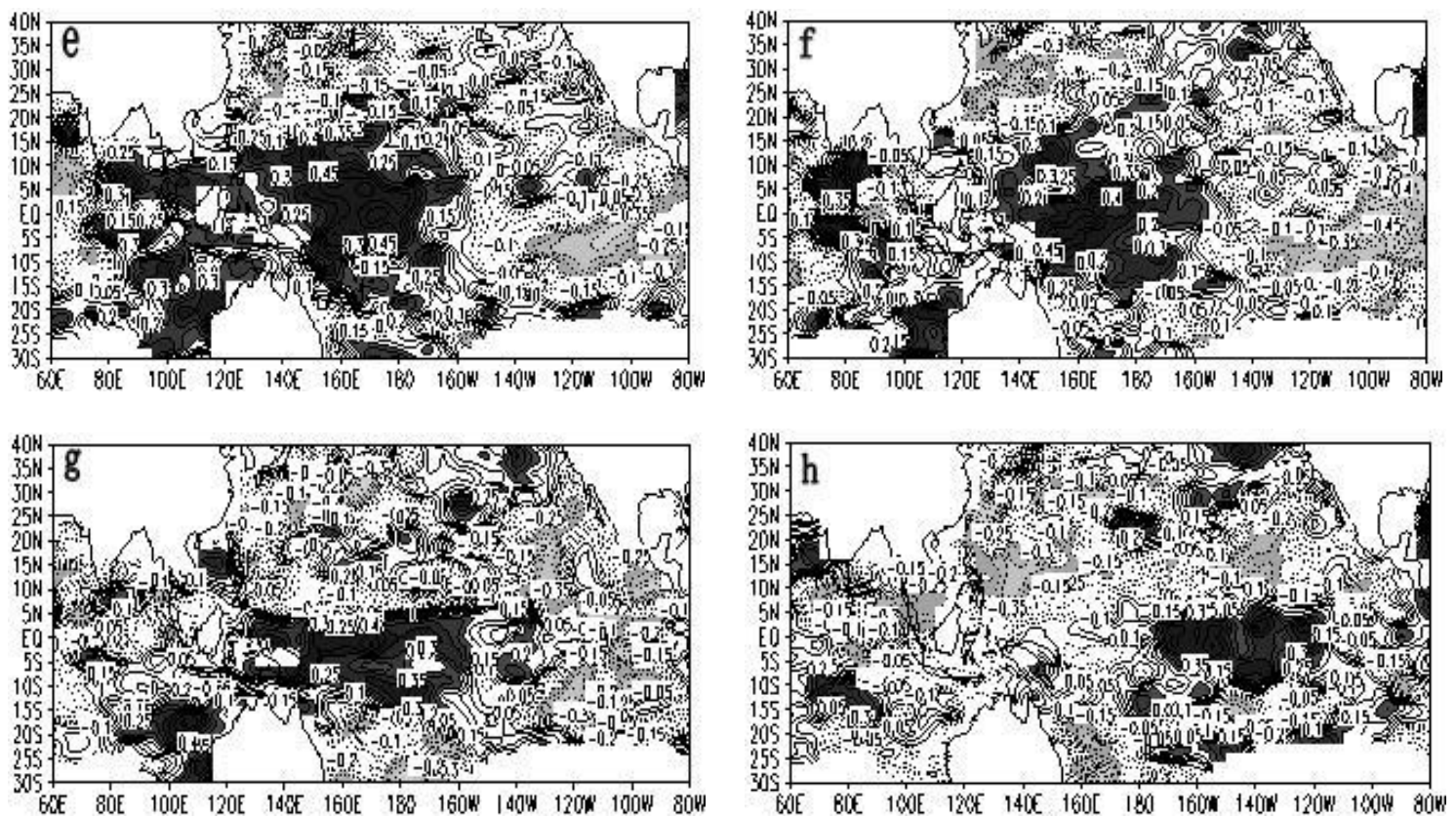

Figure 3. The distributions of the correlation coefficients between the East Asia summer monsoon index and the subsurface ocean temperature

According to Figure 3, the manifestation of correlation field at $40 \mathrm{~m}$ and $120 \mathrm{~m}$ from the Pacific Ocean to the Indian Ocean in tropics was different. When the sea temperature ahead of monsoon, the East Indian Ocean, Arabian Sea and North-western Australia's Waters on the equator at $40 \mathrm{~m}$ demonstrated a negative correlation, while at $120 \mathrm{~m}$, it demonstrated a positive correlation. When the sea temperature and monsoon in the corresponding period, Western Australia's Waters, near the island of Sri Lanka and the Central Pacific Ocean on the equator at $40 \mathrm{~m}$ demonstrated a negative correlation, while at $120 \mathrm{~m}$, it demonstrated a positive correlation. That's to say, the strength of EASM has different influences on different levels on tropical sea subsurface (Chen et al., 2011; Xu et al., 2016). But the distribution of these two kinds of correlation field in the East Pacific was about the same.

The positive and negative correlation zone moved over time from West to East. When the sea temperature ahead of monsoon for 7 month, the Central East Indian Ocean was the negative correlation center at 40m, it was linked with the negative zone in Northern South China Sea and the Waters of South Japan and moved to the West Pacific Ocean when the sea temperature lagged behind monsoon for 4 months. When the sea temperature ahead of monsoon for 7 months, the West Pacific Ocean $15^{\circ} \mathrm{S} \sim 15^{\circ} \mathrm{N}$ is the significant positive correlation field and it moved to East Pacific when the sea temperature lagged behind monsoon for 4 months and narrowed to the area of $5^{\circ} \mathrm{S} \sim 10^{\circ} \mathrm{N}$. The positive correlation zone of the West Pacific at $120 \mathrm{~m}$ moved to southeast monthly. When the sea temperature ahead of monsoon, the positive correlation field at $40 \mathrm{~m}$ moved eastward to near the date line and reached near $160^{\circ} \mathrm{W}$ at $120 \mathrm{~m}$. We can conclude that the positive 
correlation field at $120 \mathrm{~m}$ was ahead of that was at $40 \mathrm{~m}$ and it was overlapped with the positive correlation field at $40 \mathrm{~m}$ when the sea temperature lagged behind monsoon for 4 months. At that time, the correlation field in above and below of the Indian Ocean was basically the same. In combination with Figure 2 whose distribution pattern of correlation field changed over time, this paper concluded that the positive and negative correlation zone's moving from West to East made the correlation field that the sea temperature ahead of monsoon for 7 months and lagged behind monsoon for 4 months associated with the transition of " -+- " to " + - +".

In combination with the related analysis of the correlation field that the sea temperature ahead of monsoon for 7 months and lagged behind monsoon for 4 months in Figure 2 and Figure 3, this paper concluded that the positive (negative) sea temperature of the West Pacific Ocean to the East Indian Ocean was anomaly in autumn and winter of the previous year; the negative (positive) anomaly on the Central Indian Ocean and the East Pacific Ocean can easily lead to strong (weak) summer monsoon in the next year. Conversely, strong (weak) summer monsoon could accelerate the change the temperature of the sea on the East Indian Ocean and the West Pacific (from cold to warm) and the Central Indian Ocean and the East Pacific Ocean (from warm to cold) (Yuan and Yang, 2012; Yuan et al., 2012). It was evident at 120m, which meant that the sea temperature in this level and EASM have close relationship.

\section{The Interaction of SOT from the Pacific Ocean to the Indian Ocean in the Tropics and EASM Circulation}

To testify the above conclusion and clearly discern the circulation pattern in the year of strong EASM and weak EASM and the abnormalities of SOT. Then this paper made a composite analysis of anomaly wind field at $850 \mathrm{hPa}$ and sea temperature anomaly at $120 \mathrm{~m}$ in the year of strong EASM and weak EASM to investigate the interaction of SOT and EASM circulation.

To reflect the annual variation of EASM objectively and quantitatively, it was necessary to represent the variation of monsoon with index. This paper applied the EASM index that defined by Zhang et al. (2003) (Fig. 1) and made a composite analysis of the year of strong EASM (in 1972, 1978, 1984, 1985, 1986) and the year of weak EASM (in 1956, 1980, 1983, 1995, 1998). Figure 4 was the composite graph of wind anomaly in the year of strong summer monsoon and weak summer monsoon at $850 \mathrm{hPa}$ and Figure 5 was the corresponding composite graph of sea temperature anomaly at $120 \mathrm{~m}$.

In autumn and winter of the previous year, the year of strong summer monsoon, the Indian Ocean on the equator was the westerly anomaly and the Indian Ocean on the equator was the easterly anomaly (Fig. 4a). The vertical velocity anomaly over the East Pacific Region on the equator were descending motions while over the West Pacific Region on the equator, there were ascending motions (Fig. 6a). It showed that Walker circulation on the Pacific Ocean Region on the equator was enhanced; the West Pacific Ocean to the East Indian Ocean region was strong positive sea temperature anomaly and it demonstrated the phenomenon of La Nina-like (Fig. 5a). In Spring, the westerly wind 
anomaly on the Indian Ocean was weakening and moved to northeast to Malay peninsula and turned into west wind anomaly air current; the westerly wind anomaly over the West Pacific Ocean stretched toward the northeast and formed strong west wind anomaly air current; the easterly wind anomaly on the East Pacific Ocean on the equator was weakening and there were negative sea temperature anomaly on the East Indian Ocean, Northern South China Sea, Taiwan and Eastern Luzon Island's Waters, the anomaly center that was equal or greater than $1{ }^{\circ} \mathrm{C}$ in warm pool region moved from west of the date line to east to near $140^{\circ} \mathrm{W}$ (Fig. 5 b).

In summer, there was a closed cyclonic anomaly circulation in the East Asia to Pacific Ocean in tropics (Fig. 4c). If there was a cyclonic anomaly circulation in the East Asian tropical monsoon region, it showed that EASM circulation was strengthen (Zhang and Wang, 2006); if there was a west wind anomaly air current on the East Pacific Ocean on the equator and the east wind was weakening, the whole East Indian Ocean on the equator at $120 \mathrm{~m}$ showed a phenomenon of negative sea temperature anomaly. The anomaly center that was equal or greater than $1{ }^{\circ} \mathrm{C}$ further strengthened (Fig. 5c). In autumn and winter, there was an east wind anomaly air current on the Indian Ocean on the equator and the west wind was weakening, which was called as weak east wind (Fig. 4d). The vertical velocity anomaly over the East Pacific Ocean region on the equator were ascending motions, while there were descending motions over the West Pacific Region on the equator (Fig. 6b). It showed that Walker circulation was weakened; the most area of the Central Indian Ocean to the Southeast Pacific Ocean at 120m was positive sea temperature anomaly and the WPWP was strong negative sea temperature anomaly, the phenomenon of El Nino-like was formed (Fig. 5d) (Kug et al., 2009; Chen et al., 2011).
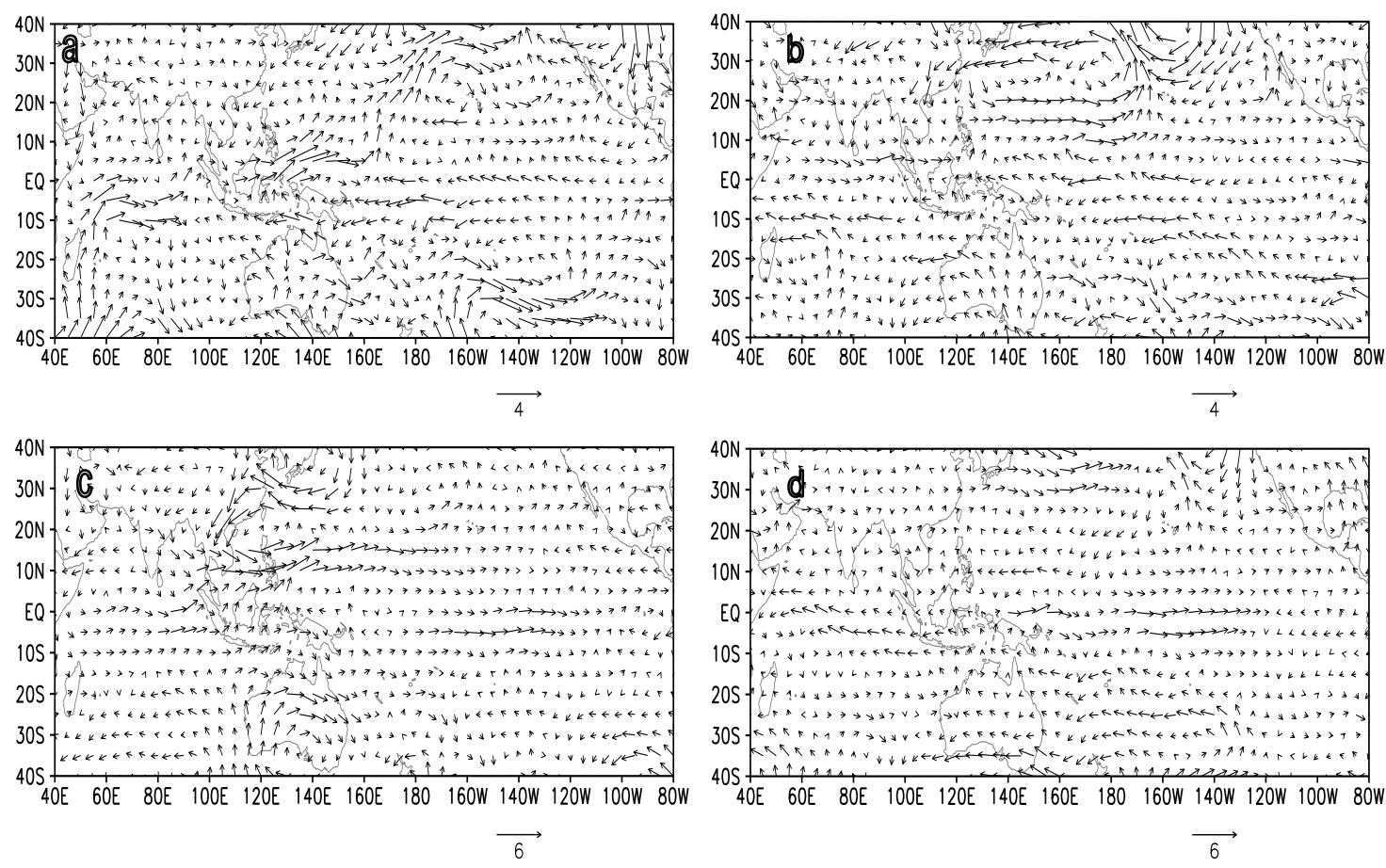

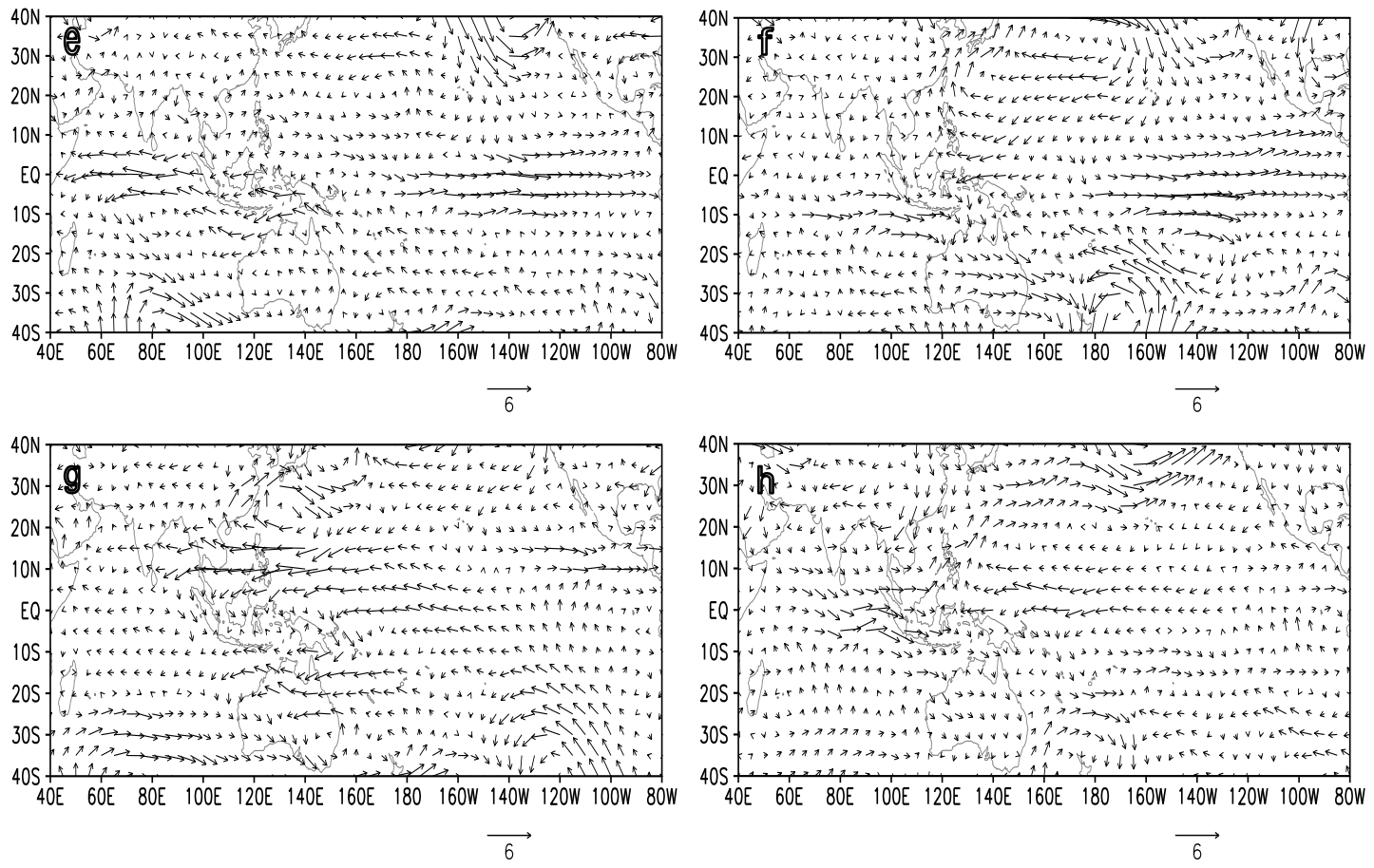

Figure 4. Composite anomalous wind at $850 \mathrm{hPa}:(a \sim d)$ strong East Asia summer monsoon case: $(e \sim h)$ weak East Asia summer monsoon case (from front to back:last December, this April, July and November. unit: $m \cdot s^{-1}$ )

The characteristic of circulation pattern of the year of weak summer monsoon to low-level troposphere was in reverse. In autumn and winter of the previous year, there was an east wind anomaly air current on the Indian Ocean on the equator and the "Maritime Continent" in Indonesia and the east wind was weakening (Fig. 4e), Walker circulation was weakened (Fig. 6c); the West Pacific Ocean to the East Indian Ocean on the equator was a strong negative sea temperature anomaly. The south of $10^{\circ} \mathrm{N}$ and the east of $170^{\circ} \mathrm{W}$ was strong positive anomaly and showed the phenomenon of El Nino-like (Fig. 5e). In Spring, there was a west wind anomaly air current as east anomaly left the East Indian Ocean on the equator and there was a easterly wind anomaly over the West Pacific Ocean Region. At the same time, the negative anomaly of the sea temperature on the East Indian Ocean was weakened, and there was a positive anomaly Taiwan and Eastern Luzon Island's Waters that was equal or greater than $0.4^{\circ} \mathrm{C}$. In Summer, there was a closed anticyclone anomaly circulation in the East Asia to Pacific Ocean Region in tropics (Fig. 4g). If there was a anticyclone anomaly circulation in EASM Region, the EASM circulation was weakened (Zhang and Wang, 2006), and there was an east wind anomaly air current on the Pacific Ocean Region on the equator; the positive sea temperature anomaly on the West Pacific Ocean to the East Indian Ocean was formed and the negative center that was less than or equal to $-0.4^{\circ} \mathrm{C}$ moved to the south of $10^{\circ} \mathrm{N}$ and the east of $170^{\circ} \mathrm{E}$ (Fig. $5 \mathrm{~g}$ ). In autumn and winter, there was still an east wind anomaly air current on the Pacific Ocean region on the equator, Walker circulation was further strengthened (Fig. 6d); there was a strong positive sea temperature on the West Pacific 
Ocean Region on the equator; the most of the Central Indian Ocean and the East Pacific Ocean region was a negative sea temperature anomaly, the phenomenon of La Nina-like was formed (Fig. 5h) (Kug et al., 2009; Chen et al., 2011).
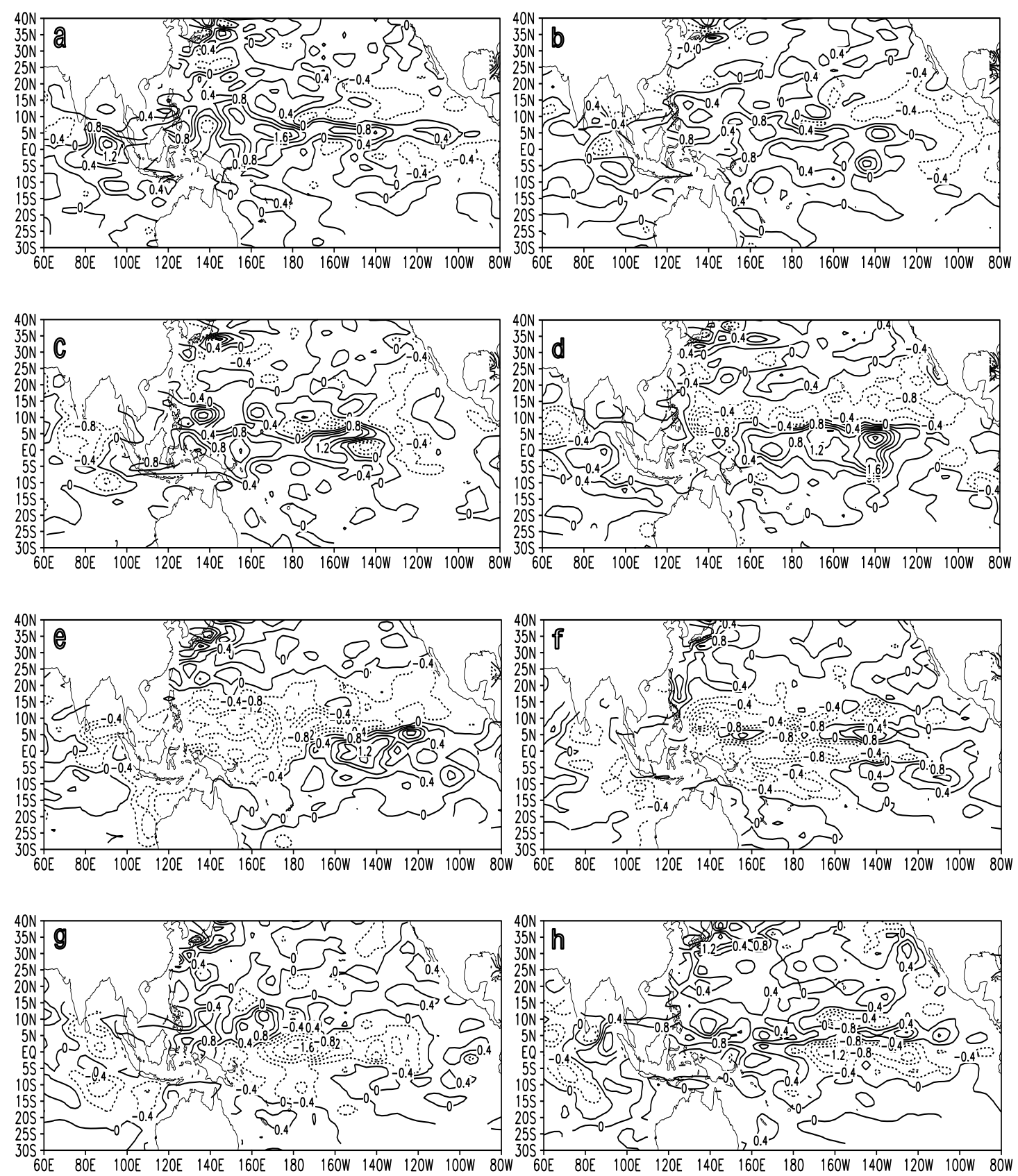

Figure 5. Composite anomalous subsurface ocean temperature at 120m: $(a \sim d)$ strong East Asia summer monsoon case: $(e \sim h)$ weak East Asia summer monsoon case (from front to back:last December, this April, July and November) 

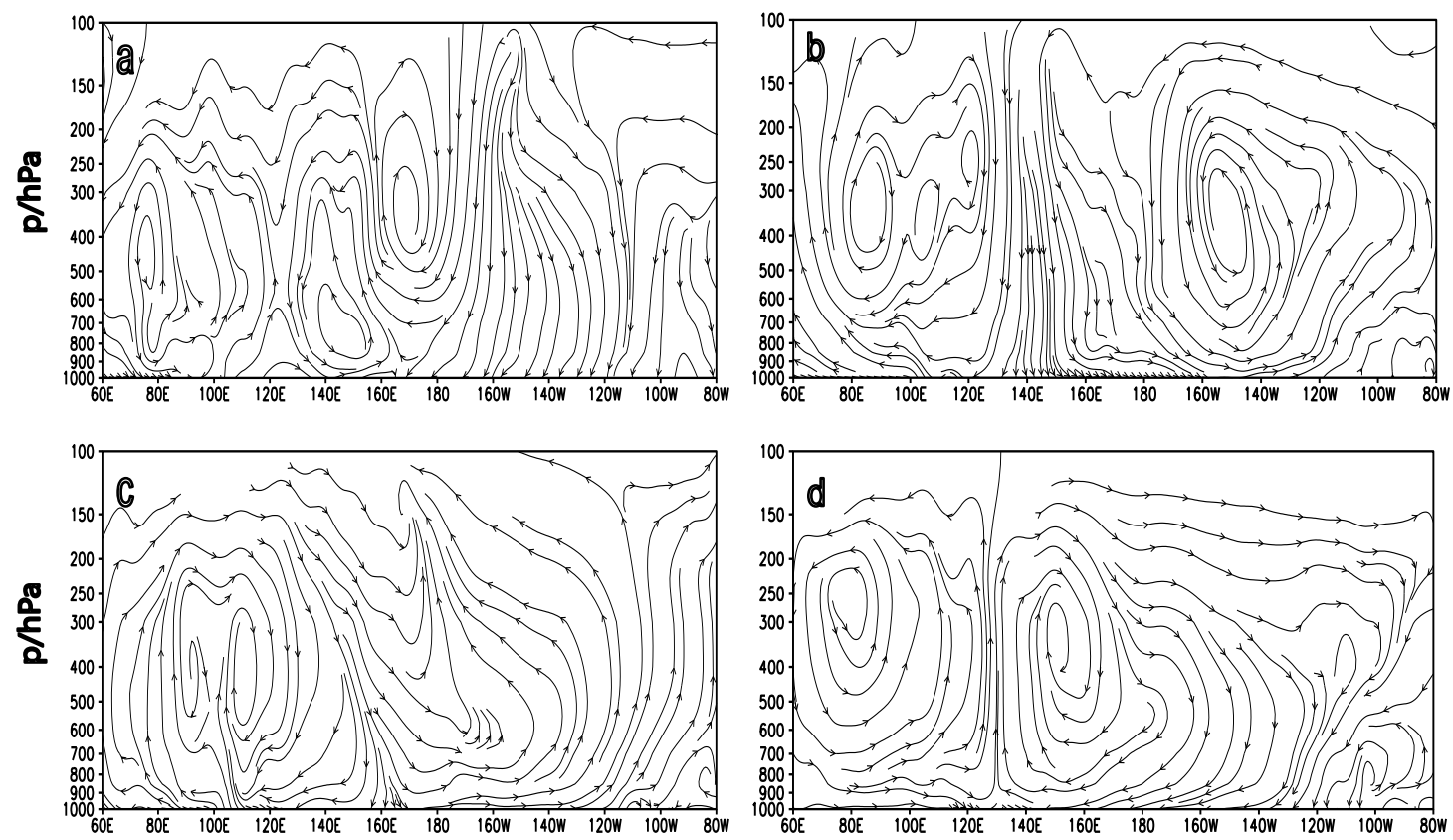

Figure 6. Height-longitude section for anomalous vertical velocity averaged over ( $50 \mathrm{~S}-5 \mathrm{o} \mathrm{N}$ ) $a \sim b$ last December and this November in strong East Asian summer monsoon case: $c \sim d$ last December and this November in weak East Asian summer monsoon case

\section{Discussion}

According to the analysis of this paper, we can get some meaningful information on EASM and ENSO prediction: with the strengthening of Walker Circulation on the East Pacific Ocean on the equator in autumn and winter of the previous year, the sea temperature from the East Indian Ocean to West Pacific Ocean Region on the equator at $120 \mathrm{~m}$ was warming intensively. Meanwhile, the strong westerly wind on the Indian Ocean to the West Pacific motivated the warm Kelvin Wave moved eastward (Huang et al., 1996, 2011), the high temperature center on the West Pacific Ocean began to move to the east, from March to April, there was an easterly wind air current in the East Pacific; Walker Circulation was strengthened and the updraft over the West Pacific Ocean was strengthened, too. Which created the conditions of the strong summer monsoon (Xu et al., 2016). From July to September, there was a weak east wind on the East Pacific Ocean region and Walker Circulation was weakened, and the strong summer monsoon might accelerate the eastward of Kelvin Wave and cause the sea temperature of the West Pacific Ocean reduced and that of the East Pacific Ocean raised and the phenomenon of El Nino-like was formed ( $\mathrm{Li}$ and $\mathrm{Mu}, 1999 ; \mathrm{Mu}$ and $\mathrm{Li}, 2000$ ). Reversely, in autumn and winter of the previous year, the weak west wind on the Indian Ocean on the equator at $120 \mathrm{~m}$, the weak east wind on the East Pacific Ocean and Walker Circulation were weakened, the brace that maintaining the terrain of the sea level of the Pacific Ocean that high in east and low in west was damaged, the warm water of the West Pacific Ocean spread to the east quickly and caused the East Pacific Ocean getting warm and the west 
Pacific Ocean getting cold. In April, the east wind anomaly air current left the East Indian Ocean on the equator, the west wind over the West Pacific Ocean was weakened, the part of the warm pool was warming up. At the same time, the East Pacific Ocean on the equator was still a west wind anomaly air current, Walker Circulation and the updraft over the West Pacific Ocean Region were weakened, which created the conditions of the weak summer monsoon (Xu et al., 2016). From July to September, the east wind on the East Pacific Ocean region was strengthened and Walker Circulation was also strengthened, which cause the sea temperature of the West Pacific Ocean to the East Indian Ocean raised and the phenomenon of La Nina-like was formed.

Through the analysis of the upper sea temperature from tropical Pacific Ocean to Indian Ocean, this paper has found that the sea temperature at $120 \mathrm{~m}$ is the closest relationship with the intensity of EASM. The study of SOT is more valuable because of its higher stability and memorability. At the same time, the EASM seriously affects the weather and climate in China (Guo et al., 2003; Li et al., 2011), so there is practical significance on forecasting the summer monsoon strength by analyzing the SOT to forecast the weather or climatic conditions. This paper also has found that the strength of EASM can change the distribution of SOT in turn. As for the relationship between the distribution of SOT from tropical Pacific Ocean to Indian Ocean and the ENSO cycle would be the focus of the next work.

In this paper, the studies not only regard SOT as air-sea interaction in the tropical Pacific region, but also begin to pay close attention to the interaction of tropical Indian Ocean and EASM through the atmospheric bridge. However, the relationship between SOT and EASM is not only a tropical problem (Yeh et al., 2009; Chen et al., 2013). There is a lack of further understanding of the influence mechanism of air-sea system in off-tropical area on EASM. Therefore, the interaction between SOT in off-tropical area and EASM may be an important research topic in the future. In addition, the influence mechanism of distribution of SOT and ENSO events on the global weather would receive significant attention.

\section{Conclusion}

This paper focused on the correlation of SOT from the Pacific Ocean to the Indian Ocean in the tropics and EASM and discussed the interactions of them. It turned out that:

The analysis of the correlation of EASM index and the SOT from the Pacific Ocean to the Indian Ocean in the tropics showed that the best correlation between the Central Indian Ocean, the Indian Ocean and the West Pacific Ocean to the East Indian Ocean and EASM index is at $120 \mathrm{~m}$, the correlation coefficient is weakening above $120 \mathrm{~m}$ or below 120m (Zhang et al., 2001b, 2002); The positive and negative correlation zone move from west to east over time from the Pacific Ocean to the Indian Ocean in tropics; the correlation distribution of the region on the Indian Ocean, the West Pacific Ocean to the East Pacific Ocean, the East Pacific Ocean and the monsoon index associated with the transition of "- + -" to "+ ++ " and in this process, the positive correlation at $120 \mathrm{~m}$ is exceeded that at $40 \mathrm{~m}$. 
The sea temperature on the West Pacific Ocean to the East Indian Ocean at $120 \mathrm{~m}$ is a little high, while the sea temperature on the Central Indian Ocean and the East Pacific Ocean is a little low, that was to say, the distribution of the sea temperature is demonstrated a phenomenon of La Nina-like, it is easy to cause strong summer monsoon in the next year. Moreover, it is easy to turn into the phenomenon of El Nino-like in autumn and winter. Reversely, the sea temperature from the West Pacific Ocean to the East Indian Ocean on the equator is a little low, while the sea temperature on the Central Indian Ocean and the East Pacific Ocean was a little high, that is to say, the distribution of the sea temperature demonstrates a phenomenon of El Nino-like, it is easy to cause weak summer monsoon in the next year. Moreover, it is easy to turn into the phenomenon of La Nina-like in autumn and winter. Which mainly reflects in the strength of the east wind on the East Pacific Ocean on the equator, the strength difference between the west wind on the Indian Ocean to the West Pacific Ocean and Walker Circulation. This paper can conclude that the distribution of SOT in tropics has influence on EASM; the abnormalities of EASM will change the thermal regime of sea; EASM and the SOT from the Pacific Ocean to the Indian Ocean in the tropics have interactions with each other (Huang et al., 1996; Zong et al., 2010), but the interaction mechanism of them and the relationship between the SOT distribution from the tropical Pacific Ocean to the Indian Ocean and the ENSO cycle need further exploration and study.

Acknowledgements. This work was supported in part by the China Civil Aviation Flight Technology and Flight Safety Research Base Open Fund Project (F2016KF02), China Civil Aviation Flight University Youth Fund Project (Q2012-071), National Natural Science Foundation of China (No. 61671030, U1536115, U1536207), China 863 High-tech Programme (Project No. 2015AA016002). The authors wish to thank anonymous reviewers for their valuable comments and suggestions that improved this paper.

\section{REFERENCES}

[1] Cai, Y., Zhang, J., Yu, W. (2005): An Analysis of Temperature anomaly in 0-400m Layer of Equatorial Indian and Pacific Oceans. - Journal of Tropical Oceanography 24(4): 60-66.

[2] Chen, G., Huang, R. (2008): Influence of monsoon over the warm pool on interannual variation on tropical cyclone activity over the western North Pacific. - Adv. Atmos. Sci. 25(2): 319-328.

[3] Chen, Y., Li, Q., Zhao, Y., et al. (2010): Signal Pathway of Interannual Variability of the Pacific Subsurface Ocean Temperature Anomalies and the ENSO Cycle. - Chinese Journal of Oceanology and Limnology 41(5): 657-666.

[4] Chen, Y., Zhao, Y., Wang, F., et al. (2011): The decadal variability of tropical pacific subsurface ocean temperature anomaly and its impact on climate of china. - Journal of tropical meteorology 27(6): 785-796.

[5] Chen, L., Yuan, Y., Yang, M., et al. (2013): A Review of Physical Mechanisms of the Global SSTA Impact on EASM. - Journal of Applied Meteorological Science 24(5): 521-532.

[6] Guo, Q., Cai, J., Shao, X., et al. (2003): Interdecadal variability of East Asian summer 
monsoon and its impact on the climate of China. - Acta Geographica Sinica 58(4): 569-576.

[7] Huang, R, Fu, Y., Zhan, X. (1996): Asian Monsoon and ENSO Cycle Interaction. Climatic and Environmental Research 1(1): 38-54.

[8] Huang, W., Cao, J., Huang, X., et al. (2011): The evolution of $20^{\circ} \mathrm{C}$ isothermal depth in tropical pacific and its association with ENSO cycle. - Journal of Tropical Meteorology 27(1): 82-88.

[9] Huang, R., Huangfu, J., Liu, Y., et al. (2016): Progress in recent research on the processes and physical mechanisms involved in the influence of the western Pacific warm pool on the monsoon trough and tropical cyclone activity over the western North Pacific. Chinese Journal of Atmospheric Sciences 40(5): 877-896.

[10] Huang, R., Sun, F. (1994a): Impact of the Convective Activities over the Western Tropical Pacific Warm Pool on the Intraseasonal Variability of the East Asian Summer Monsoon. - Chinese Journal of Atmospheric Sciences 18(4): 456-463.

[11] Huang, R., Sun, F. (1994b): Impacts of the Thermal State and the Convective Activities in the Tropical Western Warm Pool on the Summer Climate Anomalies in East Asia. Chinese Journal of Atmospheric Sciences 18(2): 141-151.

[12] Jin, Z., Chen, J. (2002): A Composite Study of the Influence of SST Warm Anomalies over the Western Pacific Warm Pool on Asian Summer Monsoon. - Chinese Journal of Atmospheric Sciences 26(1): 57-68.

[13] Kug, J. S., Jin, F. F., An, S. I. (2009): Two types of El Nino events: Cold tongue E1 Nino and warm pool E1 Nino. - J Climate 22: 1499-1515.

[14] Li, C., Mu, M. (1999): El Nino Occurrence and Sub-Surface Ocean Temperature Anomalies in the Pacific Warm Pool. - Chinese Journal of Atmospheric Sciences 23(5): 513-521.

[15] Li, S., Shou, S. (2000): Equatorial Eastern Pacific SST and Analysis on Causes of Summer Floods/Droughts in the Changjiang and Huaihe River Basin. - Journal of Applied Meteorological Science 11(3): 331-338.

[16] Li, C., Mu, M., Zhou, G., et al. (2008): Mechanism and prediction studies of the ENSO. Chinese Journal of Atmospheric Sciences(in Chinese) 32(4): 761-781.

[17] Li, Q., Wei, F., Li, D. (2011): Interdecadal variations of East Asian summer monsoon and drought/flood distribution over Eastern China in last 159 years. - Acta Geographica Sinica 66(1): 25-37.

[18] Li, J., Ren, R., Qi, Y., et al. (2013): Progress in air-land-sea interactions in Asia and their role in global and Asian climate change. - Chinese Journal of Atmospheric Sciences 37(2): 518-538.

[19] Li, X., Li, C. (2014): Occurrence of two types of El Nino events and the subsurface ocean temperature anomalies in the equatorial Pacific. - Chinese Science Bulletin 59(21): 2098-2107.

[20] Mcphaden, M. J. (1999): Genesis and evolution of the 1997 98 El Niño. - Science 283(5404): 950-953.

[21] Mu, M., Li, C. (2000): Interactions between Subsurface Ocean Temperature Anomalies in the Western Pacific Warm Pool and ENSO Cycle. - Chinese Journal of Atmospheric Sciences 24(4): 447-460.

[22] Qian, W H. (2000): Dry/wet alternation and global monsoon. - Geophysical Research Letters 27(22) : 3679-3682.

[23] Shan, C., Li, Y., Ren, R., et al. (2016): Characteristics of the West Pacific warm pool thermal condition and its effects on the ENSO events based on the GODAS data. Journal of the Meteorological Sciences 36(5): 674-680.

[24] Wang, B., Wu, R. G., Fu, X. H. (2000): Pacific-East Asian teleconnection: how does ENSO affect East Asian climate? - Journal of Climate 13(9): 1517-1536. 
[25] Wang, S. (2010): Global monsoon. - Advances in Climate Change Research 6(6): 473-474.

[26] Xie, S.-P., Du, Y., Huang, G., et al. (2010): Decadal Shift in El Nino Influences on Indo-Western Pacific and East Asian Climate in the 1970s. - Journal of Climate 23(12):3352-3368.

[27] Xu, P., Feng, J., Chen, W. (2016): Asymmetric roles of ENSO in the link between the East Asian winter monsoon and the following summer monsoon. - Chinese Journal of Atmospheric Sciences 40(4): 831-840.

[28] Yeh, S. W., Kug, J. S., Dewitte, B., et al. (2009): El Nino in a changing climate. - Nature 461:511-514.

[29] Yuan, Y., Yang, H., Li, C. (2012): Study of EI Nino events of different types and their potential impact on the following summer precipitation in China. - Acta Meteorologica Sinica 70(3): 467-478.

[30] Yuan, Y., Yang, S. (2012): Impacts of different types of El Nino on the East Asian climate: Focus on ENSO cycles. - J Climate 25: 7702-7722.

[31] Zhang, R., Akimasa, S., Masahide, K. (1999): A diagnostic study of the impact of EI Nino on the precipitation in China. - Adv. Atmos. Sci. 16(2): 229-241.

[32] Zhang, X., Li, J., Ding, Y., et al. (2001a): A Study of Circulation Characteristics and Index of South China Sea Summer Monsoon. - Journal of Meteorological Research 15(4): 450-464.

[33] Zhang, X., Li, J., Wang, D. (2001b): The relationship between the thermocline depth of tropical ocean and the intensity of the South China Sea summer monsoon. - Acta Oceanologica Sinica 23(3): 26-34.

[34] Zhang, X., Li, J., Wang, D. (2002): Research on Relationship between SOT in Tropical Area and SCS Summer Monsoon. - Journal of Meteorological Research 60(2): 156-163.

[35] Zhang, Q., Tao, S., Chen, L. (2003): The Inter-annual Variability of East Asian Summer Monsoon Indices and its Association with the Pattern of General Circulation over East Asia. - Journal of Meteorological Research 61(4): 559-568.

[36] Zhang, Q., Wang, Y. (2006): The Response of East Asian Monsoon Circulation between Winter and Summer to Sea Surface Temperature over the Pacific Ocean. - Climatic and Environmental Research 11(4): 487-498.

[37] Zong, H., Chen, L., Zhang, Q. (2010): The instability of the interannual relationship between ENSO and the summer rainfall in China. - Chinese Journal of Atmospheric Sciences 34(1): 184-192. 